\title{
CF(x): A first-principles study of structural patterns arising during synthetic growth
}

Gueorgui Kostov Gueorguiev, Cecilia Goyenola, Susann Schmidt and Lars Hultman

\section{Linköping University Post Print}

N.B.: When citing this work, cite the original article.

Original Publication:

Gueorgui Kostov Gueorguiev, Cecilia Goyenola, Susann Schmidt and Lars Hultman, CF(x): A first-principles study of structural patterns arising during synthetic growth, 2011, Chemical Physics Letters, (516), 1-3, 62-67.

http://dx.doi.org/10.1016/j.cplett.2011.09.045

Copyright: Elsevier

http://www.elsevier.com/

Postprint available at: Linköping University Electronic Press

http://urn.kb.se/resolve?urn=urn:nbn:se:liu:diva-72251 


\title{
$\mathrm{CF}_{\mathrm{x}}$ : A first-principles study of structural patterns arising during synthetic growth
}

\author{
G. K. Gueorguiev, C. Goyenola, S. Schmidt, L. Hultman \\ Department of Physics, Chemistry and Biology (IFM), Linköping University, SE 58183 , \\ Linköping, Sweden
}

\begin{abstract}
Structural and bonding patterns arising from the incorporation of fluorine atoms in a graphene-like network relevant to the deposition of carbon fluoride $\left(\mathrm{CF}_{\mathrm{x}}\right)$ films were addressed by first-principles calculations. We find that large $\mathrm{N}$-member $(\mathrm{N}=8-12)$ rings, defects by sheet branching, and defects associated with bond rotation pertain to $\mathrm{CF}_{\mathrm{x}}$. The cohesive energy gains associated with these patterns are $\sim 0.2-0.4 \mathrm{eV} /$ at, which is similar to those for a wide range of defects in other C-based nanostructured solids. Fullerene-like $\mathrm{CF}_{\mathrm{x}}$ is predicted for $\mathrm{F}$ concentrations below $\sim 10$ at. $\%$, while $\mathrm{CF}_{\mathrm{x}}$ compounds with higher F content are predominantly amorphous or polymeric.
\end{abstract}




\section{INTRODUCTION}

Carbon-based fullerene-like (FL) compounds represent a novel class of thin solid film materials offering remarkable mechanical properties such as resilience and hardness $[1,2]$ as in carbon nitride $\left(\mathrm{CN}_{\mathrm{x}}\right)[1,3,4]$ and phosphorus carbide $\left(\mathrm{CP}_{\mathrm{x}}\right)[2,5,6]$. The substitution of $\mathrm{C}$ by, e.g., N, P or S [7] in FL compounds promotes defects such as combinations of pentagons $[4,6,7]$, thus leading to bent graphene sheets and crosslinkages resulting from $\mathrm{sp}^{3}$-hybridization between the $\mathrm{C}$ atoms within the $\mathrm{sp}^{2}$-coordinated sheets. The deposition method of choice for these compounds is reactive magnetron sputtering. During deposition, precursors supplied by the reactive gas and species formed by reactions on the $\mathrm{C}$-containing sputtering target or in the deposition chamber $\left(\mathrm{C}_{\mathrm{m}} \mathrm{X}_{\mathrm{n}} ; \mathrm{X}\right.$ $=\mathrm{N}, \mathrm{P}, \mathrm{S}$ in our example) become bonded by different likelihood to the various dangling bonds available on the growing film surface, thus determining the formation of the film structure after bonding relaxation.

We developed the Synthetic Growth Concept (SGC) $[4,6,8,9]$ based on the Density Functional Theory for simulations of film formation during vapor phase deposition aiming to predict the feasibility of new FL compounds and to guide their deposition in order to tailor their properties. SGC treats structural evolution by sequential steps of atomic rearrangement where each step is assigned according to the previous relaxed states. The properties of precursors for a given compound are described quantitatively together with their interaction with the film during formation of solid phases. By its basic concept, the SGC is easily transferable to other inherently nanostructured systems; it has been successfully applied to Si-metal nano-templates for cluster-assembled materials [10, 
11], while its possible application to such different classes of nano-scaled materials as, e.g., silicene clusters (an all-Si analogue of graphene) [12], or Si-substituted benzenes and their transition-metal complexes [13] is expected to be straightforward.

Within the context of carbon-based thin films, fluorine represents significant interest as a dopant element. Compared to $\mathrm{C}$ as well as to $\mathrm{N}, \mathrm{P}$, and $\mathrm{S}$, fluorine possesses different bonding properties (more valence electrons) as well as much higher electronegativity and higher chemical reactivity. Consequently, incorporation of $\mathrm{F}$ atoms in $\mathrm{C}$ matrices is expected to lead to substantial structural changes and to altered properties. Synthesizing polymeric, amorphous or even FL carbon fluoride $\left(\mathrm{CF}_{\mathrm{x}}\right)$ may lead to a new material as important as Teflon.

Previously, $\mathrm{CF}_{\mathrm{x}}$ thin films were mainly synthesized by plasma enhanced chemical vapor deposition or reactive RF-sputtering techniques $[14,15] . \mathrm{CF}_{\mathrm{x}}$ films with increasing Fcontent $(\mathrm{x}>0.25)$ were found to exhibit an increasingly softer polymeric structure attributed to the higher amount of C-F bonds $[14,16,17] . \mathrm{CF}_{\mathrm{x}}$ films with $\mathrm{x}<0.25$, on the other hand, exhibit properties such as low friction coefficient, wear resistance combined with moderate hardness as well as biocompatibility [14].

Recently, we have successfully applied reactive high power pulsed magnetron sputtering (HiPIMS) for the synthesis of $\mathrm{CF}_{\mathrm{x}}\left(\mathrm{CF}_{\mathrm{x}}, 0.16 \leq \mathrm{x} \leq 0.35\right)$ films in an Ar/tetrafluorocarbon $\left(\mathrm{CF}_{4}\right)$ atmosphere. Because of the increased ion flux, HiPIMS may offer potential to incorporate $\mathrm{F}$ firmly into the $\mathrm{C}$ matrix. In order to understand and control the process of F-incorporation in $\mathrm{CF}_{\mathrm{x}}$ films, we carried out $\mathrm{SGC}$ calculations to 
predict and explain the relative stability of precursor species resulting from dissociation of the $\mathrm{CF}_{4}$ molecules used as a fluorine source. Also some typical structural defects resulting from the incorporation of $\mathrm{F}$ atoms in a perfect hexagonal carbon (graphene-like) network were assessed [18]. Such defects clearly distinguish $\mathrm{CF}_{\mathrm{x}}$ from other carbonbased nanostructured compounds such as $\mathrm{CN}_{\mathrm{x}}[4]$ and $\mathrm{CP}_{\mathrm{x}}[6]$.

The scope of this work is to evaluate and systematize the type of structural patterns arising from the incorporation of $\mathrm{F}$ atoms in a graphene-like network. In contrast to recent works dedicated to computer simulations of fluorination of relatively small organic molecules $[19,20,21]$, in our calculations we employ considerably larger graphene-like model systems based on coronene and corannulene-molecules. The nomenclature of four typical structural $\mathrm{CF}_{\mathrm{x}}$ patterns discussed here corroborates the understanding of the growth mechanism of magnetron sputtered $\mathrm{CF}_{\mathrm{x}}$ films and provides suggestions how to control the $\mathrm{CF}_{\mathrm{x}}$ films' structure. In the resulting structural pattern classification the defects in the F-doped graphene-like network are found to belong to one of the following patterns: large ring defects, "branching"-type of graphene-sheet disruption, an "uncomplicated" C-F bond rotation, and an F atom belonging to a ring. We define these $\mathrm{CF}_{\mathrm{x}}$ structural patterns by applying $\mathrm{SGC}$ simulations to a variety of $\mathrm{CF}_{\mathrm{x}}$ model systems. Importantly, some of the structural trends determined here by SGC calculations suggest that when the F-content in a $\mathrm{CF}_{\mathrm{x}}$ film is below $\sim 10$ at.\%, a close-order FL structure similar to that of $\mathrm{FL}_{-} \mathrm{CP}_{\mathrm{x}}[6]$ can be obtained. 


\section{THEORETICAL METHODOLOGY AND COMPUTATIONAL DETAILS}

The framework adopted for the present calculations is Density Functional Theory (DFT) mostly within its Generalized Gradient Approximation (GGA) as implemented in the Gaussian 09 code [22].

A systematic study of a variety of $\mathrm{CF}_{\mathrm{x}}(0<\mathrm{x}<0.16)$ model systems (templates) obtained by substitution of $\mathrm{C}$ atoms by $\mathrm{F}$ atoms in finite graphene-like structures was carried out by geometry optimizations. Similar coronene and corannulene-based graphene-like model systems have been successfully employed for, e.g., modeling the chemical reactivity of graphene [23, 24]; as well as for addressing FL systems [2, 7], and graphenelike nano-units [25].

The changes in the cohesive energy per atom resulting from the substitutional $\mathrm{F}$ at $\mathrm{C}$ sites were calculated for structural relaxation of a wide diversity of defects expected in doped graphene-like systems [4, 6] employing seven different templates of varying size containing combinations of pentagons, Stone-Wales (SW) defects, and even a tetragon defect.

The cohesive energy per atom $\left(E_{\text {coh/at }}\right)$ is trivially defined as the energy required for splitting the considered system into isolated atomic species divided by the number of $\mathrm{C}\left(\mathrm{N}_{\mathrm{C}}\right)$, and $\mathrm{F}$ atoms $\left(\mathrm{N}_{\mathrm{F}}\right)$ :

$$
E_{\text {cohlat }}=\frac{E_{\text {total }}-\sum_{i} E_{i, \text { total }}^{\text {isolat }}}{N_{C}+N_{F}},
$$


where $E_{\text {total }}$ is the energy of the relaxed model system, $E_{i}$ the energy of each species and $i$ represents the index of summation over system's constituent atoms. When a model system evolves by changing its structure and bonding, or by incorporating additional species, the change in its cohesive energy per atom $\Delta \mathrm{E}_{\text {coh/at }}$ is considered: $\Delta \mathrm{E}_{\text {coh/at }}=$ $\mathrm{E}_{\text {coh/at }}\left(\right.$ model system after structural evolution) $-\mathrm{E}_{\mathrm{coh} / \mathrm{at}}($ analogous model system before structural evolution). Since cohesive energies per atom are employed (Eq. 1), $\Delta \mathrm{E}_{\text {coh/at }}$ is meaningful also when new species are incorporated in the model system thus changing the number of the $\mathrm{C}$ and the $\mathrm{F}$ atoms.

At the DFT level of theory, both the GGA Perdew-Wang exchange-correlation functional (PW91) [26] and the Hybrid B3LYP functional [27] have been employed. These functionals are known to provide an accurate description of the structure and properties of carbon-based thin films $[6,8]$ as well as similar covalent systems $[28,29$, 30]. The results reported in this work were obtained employing the PW91 exchange correlation functional (and making use of the $6-31 \mathrm{G}^{* *}$ basis set augmented with polarization functions) while the B3LYP calculations were carried out for comparative purposes.

\section{RESULTS AND DISCUSSION}

\subsection{Structural patterns in $\mathbf{C F}_{\mathbf{x}}$}

The following finite graphene-like model systems were subject to incorporation of defects by the substitution of a $\mathrm{C}$ atom by an $\mathrm{F}$ atom with subsequent geometry 
relaxations: i) coronene and ii) corannulene molecules (Figs. 1a, and 1b, respectively); iii) a double pentagon defect (Fig. 1c); iv) a Stone-Wales defect (Fig. 1d); v) hexagon network (Fig. 1e), and vi) a single pentagon defect (Fig. 1f). The size of each model system employed here was chosen based on our experience in systematic studies of defects in graphene-like networks $[4,6]$, including in $\mathrm{CF}_{\mathrm{x}}[18]$ and was equal or larger than was used by others for similar material systems and properties addressed at a similar level of theory [31, 32]. In contrast to what happens in other carbon-based compounds where the dopant element differs less radically from carbon in its bonding properties (e.g., $\left.\mathrm{CN}_{\mathrm{x}}[4], \mathrm{CP}_{\mathrm{x}}[6], \mathrm{CS}_{\mathrm{x}}[7]\right)$, in the case of the carbon fluoride most of the aforementioned structural defects do not prevail after geometry relaxations due to breakage of bonds and atomic rearrangements. Consequently, in $\mathrm{CF}_{\mathrm{x}}$, instead of discussing pentagons, double pentagons, and Stone-Wales defects, a more appropriate way to address the structural features resulting from F-incorporation in the graphene-like network is to identify prevailing structural and bonding patterns associated with fluorine as a dopant. In this context and by applying the methodology of SGC $[4,6,8,9]$, we were able to identify the main structural and bonding patterns in $\mathrm{CF}_{\mathrm{x}}$.

Geometry relaxations of templates i) - vi) (Fig. 1 a-e), resulted in a set of $\mathrm{CF}_{\mathrm{x}}$ structuredefining patterns displayed in Fig. 2 while the cohesive energy gains associated with the formation of these patterns are listed in Table 1.

The diversity of structural patterns identified in $\mathrm{CF}_{\mathrm{x}}$ includes: large $\mathrm{N}$-member $(\mathrm{N}=8-$ 12) rings (Fig. 2-a1, a2); defects by branching of the model system resulting in formation of carbon chains (Fig. 2-b1), or nano-ribbons (Fig. 2-b2); structures defined by a C-F 
bond rotation at the edge of a model system (Fig. 2-c1, c2); and, a configuration comprising an $\mathrm{F}$ atom belonging to a ring (Fig. 2-d). Below, these structural patterns are described and discussed in the context of their formation and energetics.

\section{A) Large $\mathrm{N}$-member $(\mathrm{N}=8-12)$ rings}

In $\mathrm{CN}_{\mathrm{x}}$ [4], $\mathrm{CP}_{\mathrm{x}}$ [6], and $\mathrm{CS}_{\mathrm{x}}$ [7], the largest rings resulting from incorporation of dopant atoms in the graphene network are the 7-membered rings, which appear in these compounds only as an inseparable part of a Stone-Wales defect (as illustrated in Fig. 1d). In contrast, the bonding of $\mathrm{CF}_{\mathrm{x}}$ precursors to the film surface favors the opening and stabilization of 8-12 member rings, such as the 9-member ring shown in Fig. 2-a1. One of the $\mathrm{C}$ atoms belonging to this 9 -member ring is bonded to an $\mathrm{F}$ atom. It is this $\mathrm{C}-\mathrm{F}$ bond that creates a chemically reactive site in the network and stabilizes the large $\mathrm{N}$-membered ring. As the inset in Fig. 2-a1 illustrates, upon relaxation this C-F undergoes a bond rotation. Thus, in addition to its role for stabilizing a large N-member ring, the C-F bond also works as a seed for a cross-linkage between adjacent graphene sheets. The gain in $\mathrm{E}_{\mathrm{coh} / \mathrm{at}}$ resulting from the opening of the large 9-member ring shown in Fig. 2-a1, i.e., the stabilization energy of this $\mathrm{CF}_{\mathrm{x}}$ structural pattern, is $\Delta \mathrm{E}_{\mathrm{coh} / \mathrm{at}}=0.405 \mathrm{eV} / \mathrm{at}$.

A clearly distinguishable variant of the large $\mathrm{N}$-member ring defect induced by a C-F bond rotation is observed when a pure carbon pentagon ring is stabilized at the border of the N-member ring and opposite to the C-F bond (Fig. 2-a2). The strain and the curvature induced in the graphene-like network by the C-F bond rotation reduce the energy cost for a pure carbon pentagon defect, making it feasible. The gain in $\mathrm{E}_{\mathrm{coh} / \mathrm{at}}$ resulting from a 
relaxation of such a particular kind of large $\mathrm{N}$-member ring defect associated with a pure carbon pentagon is $0.190 \mathrm{eV} /$ at. It is noteworthy that while in FL compounds such as $\mathrm{CN}_{\mathrm{x}}$ [4], $\mathrm{CP}_{\mathrm{x}}[6]$, and $\mathrm{CS}_{\mathrm{x}}$ [7], the pentagon defects contain a dopant atom, in $\mathrm{CF}_{\mathrm{x}}$, although $\mathrm{F}$ atoms are not expected to be incorporated at a regular basis in ring configurations, pentagon defects may still exist. The stabilization of such pure carbon pentagons in $\mathrm{CF}_{\mathrm{x}}$ is due to an adjacent $\mathrm{C}-\mathrm{F}$ bond rotation.

\section{B) A defect by branching of a graphene sheet}

When the $\mathrm{CF}_{\mathrm{x}}$ precursors become bonded to the growing film surface, one of the possible outcomes due to the high reactivity and electronegativity of the F atom is a disruption of the graphene-like network by its branching resulting in, e.g., formation of two symmetric arms of carbon chains as shown in Fig. 2-b1. Such branching introduces an increased reactivity and a less ordered network. $\Delta \mathrm{E}_{\text {coh/at }}$ in this case is $0.383 \mathrm{eV} /$ at (Table 1$)$. This cohesive energy gain is only slightly lower than the cohesive energy gain of $0.405 \mathrm{eV} / \mathrm{at}$ associated to large $\mathrm{N}$-member ring defects suggesting a comparable prevalence of these two types of defects. The one-dimensional chains resulting from the branching defect, besides being unique to $\mathrm{CF}_{\mathrm{x}}$ (when compared to $\mathrm{CN}_{\mathrm{x}}, \mathrm{CP}_{\mathrm{x}}$, and $\mathrm{CS}_{\mathrm{x}}$ ), also bear resemblance with short polymeric chains [33] expected to play a major role in softer $\mathrm{CF}_{\mathrm{x}}$ films with polymeric character featuring F concentrations above 25 at.\% [18]. However, even if more $\mathrm{F}$ atoms are incorporated in the one-dimensional chains resulting from branching, for stochastic reasons it can not be expected that the chain will exhibit any strictly repeating $\mathrm{C}_{\mathrm{n}} \mathrm{F}_{\mathrm{m}}$-unit-cell (where $\mathrm{m}, \mathrm{n}$ are integers) like in conventional polymers 
Similarly to the case of the large N-member ring defects, the branching defect can be observed in different structural variants. A noteworthy variant of the branching defect is when the event of $\mathrm{F}$ atom incorporation induces splitting of the model system in two symmetric arms, but in this case each arm consists in a sequence of single hexagons (Fig. 2-b2) instead of a simple carbon chain. The resulting cohesive energy gain is $\Delta \mathrm{E}_{\text {coh/at }}=$ $0.161 \mathrm{eV} /$ at. There is no particular reason for the two arms resulting from the F-induced branching in Fig. 2-b2 to consist of single hexagons only, making this defect pattern illustrative for any kind of splitting of a $\mathrm{CF}_{\mathrm{x}}$ graphene sheet in two bent "semi-planes". This mechanism opens the way for split/bent graphene sheets resulting from branching defects. Such split/bent sheets (in contrast with locally curved sheets associated with, e.g., the pentagon defects, which are frequent in the FL solids [4]) are another structural feature peculiar for $\mathrm{CF}_{\mathrm{x}}$. Bent graphene planes can also cross- and/or inter-sect. Crosslinkings and inter-sections (inter-lockings) of graphene-like sheets have also been observed in $\mathrm{FL}-\mathrm{CN}_{\mathrm{x}}[4]$ and particularly in $\mathrm{FL}_{-} \mathrm{CP}_{\mathrm{x}}[6]$.

\section{C) C-F bond rotation at the edge of a model system}

We define as an "uncomplicated" C-F bond rotation a defect not belonging to the conformation of any large $\mathrm{N}$-member ring defect or to any branching defect (patterns $\mathrm{A}$ and B defined above); i.e., we call it "uncomplicated" when the C-F bond rotation is observed independently and not as a feature of any other structural pattern. Typically, such C-F bond rotation is observed at the edge of a model system. The $\mathrm{C}$ atom of this C-F 
(rotated) bond belongs to a hexagon or to a pentagon ring within the graphene-like network (Fig. 2-c1) or, alternatively, it can be externally attached to such a ring (Fig. 2c2). The "uncomplicated" C-F bond rotation is strongly suggestive for inter-sheet crosslinkages. For the bond rotation defects in Figs. 2-c1 and 2-c2, the $\Delta \mathrm{E}_{\mathrm{coh} / \mathrm{at}}$ are $1.001 \mathrm{eV} / \mathrm{at}$, and $0.296 \mathrm{eV} / \mathrm{at}$, respectively.

\section{D) An $F$ atom belonging to a ring}

When a $\mathrm{CF}_{\mathrm{x}}$ precursor (usually a $\mathrm{CF}$ dimer) becomes bonded to the dangling bonds available at the film surface a structural configuration which features an $\mathrm{F}$ atom belonging to a closed ring can be observed (Fig. 2d). In such cases, the F atom usually sticks (by $\sim 0.5-0.6 \AA$ ) outside the graphene-like sheet. This configuration can be called "an F atom belonging to a ring" to distinguish it from the three previously described patterns $\mathrm{A}, \mathrm{B}$, and $\mathrm{C}$ (in which the $\mathrm{F}$ atom never participates in a closed ring).

In contrast to all the patterns $\mathrm{A}, \mathrm{B}$, and $\mathrm{C}$ which, as certified by cohesive energy gains $\Delta \mathrm{E}_{\text {coh/at }}$ in the range of $\sim 0.2-0.4 \mathrm{eV}$ (Table 1), are stable conformations that once formed are not expected to break or suffer considerable atomic rearrangement at the typical $\mathrm{CF}_{\mathrm{x}}$ film growth conditions, the pattern D characterized by "an F atom belonging to a ring" behaves as a metastable pattern or an intermediate structural state. The gain in cohesive energy associated with the pattern $\mathrm{D}$ is $\Delta \mathrm{E}_{\mathrm{coh} / \mathrm{at}}=0.079 \mathrm{eV} / \mathrm{at}$. This value is not only the smallest in Table 1 but it is also below $0.1 \mathrm{eV} /$ at and thus closer to the thermal energies $\sim 0.04 \mathrm{eV}$ at temperatures $\left(100-200{ }^{\circ} \mathrm{C}\right)$ typical for the $\mathrm{CF}_{\mathrm{x}}$ growth environment [18]. When testing if pattern D can survive structural changes by simulation of structural 
perturbations and bonding of additional precursors in its vicinity, the energy barrier of $0.08 \mathrm{eV} /$ at can relatively easily be reached, the ring containing the $\mathrm{F}$ atom breaks by evolving to a defect structure belonging to one of the above listed patterns A, B or C.

The metastability of a closed ring incorporating an $\mathrm{F}$ atom is a structural feature specific for $\mathrm{CF}_{\mathrm{x}}$ and contrasting to the incorporation pattern for dopant atoms in $\mathrm{CN}_{\mathrm{x}}[4], \mathrm{CP}_{\mathrm{x}}[6]$, and $\mathrm{CS}_{\mathrm{x}}$ [7]. In $\mathrm{CN}_{\mathrm{x}}, \mathrm{CP}_{\mathrm{x}}$, and $\mathrm{CS}_{\mathrm{x}}$ the corresponding dopant atoms are incorporated in stable pentagon, hexagon, heptagon and even tetragon (in the case of $\mathrm{CP}_{\mathrm{x}}$ ) rings and no large $\mathrm{N}$-member $(\mathrm{N}=8-12)$ rings or branching events are observed. Thus, the $\mathrm{CF}_{\mathrm{x}}$ defect patterns set this material apart from the remaining C-based FL compounds studied theoretically $\left(\mathrm{CN}_{\mathrm{x}}[4], \mathrm{CP}_{\mathrm{x}}[6]\right.$, and $\left.\mathrm{CS}_{\mathrm{x}}[7]\right)$ and synthesized so far $\left(\mathrm{CN}_{\mathrm{x}}[1]\right.$, and $\mathrm{CP}_{\mathrm{x}}$ [2]). The metastability of a ring incorporating an $\mathrm{F}$ atom predicted for $\mathrm{CF}_{\mathrm{x}}$ can be explained by the fact that any ring-incorporated $\mathrm{F}$ atom is bonded by single bonds to two adjacent $\mathrm{C}$ atoms that, in order to keep the graphene-like network structure, are necessarily further bonded to other carbon atoms. Such a bonding pattern for an F atom is not particularly stable due to its valence configuration and its extreme electronegativity ( $\mathrm{F}$ being the most electronegative chemical element).

In general, the choice of our model systems is governed by the preference to discuss diversified variants of the same structural pattern exhibiting different kinds of defects. For instance, the structure shown in Fig. 2-a2, notable by the pure carbon pentagon, is larger than the one displayed in Fig. 2-a1 but in comparison exhibits a smaller gain in $\Delta$ Ecoh/at $(0.190 \mathrm{eV} /$ at vs. $0.405 \mathrm{eV} / \mathrm{at})$. In fact, this difference in $\Delta \mathrm{Ecoh} / \mathrm{at}$ is due to the energy cost of the pentagon incorporation, which regardless of being facilitated by the 
presence of an incorporated $\mathrm{F}$ atom still implies an energy cost of about $\sim 0.2 \mathrm{eV} / \mathrm{at}$. Similarly, differences in $\Delta$ Ecoh/at between different model systems belonging to the same structural pattern (i.e., those exhibited in Figs 2-b1, and 2-b2) are, in general, not size-dependent but instead related to variations in their defect selection and bonding features.

\subsection{Effects of $\mathbf{F}$ content on fullerene-like, amorphous and polymeric $\mathbf{C F}_{\mathbf{x}}$}

Similarly to other compounds belonging to the class of FL materials, where the C-X bond rotation $(X=N, P, S)$ is an important factor for cross-linking between the graphene-like sheets $[4,6,7]$, the $\mathrm{C}-\mathrm{F}$ bond rotation (pattern $\mathrm{C}$ ) in $\mathrm{CF}_{\mathrm{x}}$ also leads to cross-linking and inter-locking between the $\mathrm{CF}_{\mathrm{x}}$ graphene sheets. The branching of the model system (pattern B) in its variant represented by simple $\mathrm{C}$ atom chains, Fig. 2-b1, implies polymeric structure (represented by relatively short and irregular chains), while in its variant represented by split graphene-like sheet, Fig. 2-b2, directly points to inter-locking, i.e., to amorphousness of the $\mathrm{CF}_{\mathrm{x}}$ structure. Since the cohesive energy gain associated to the carbon chain structure in Fig. 2-b1 is more than twice higher $(0.363 \mathrm{eV} / \mathrm{at})$ than that associated to split sheets/nano-ribbons in Fig. 2-b2 $(0.161 \mathrm{eV} / \mathrm{at})$, it is expected that the elements of polymeric structure become more noticeable as the F concentration increases. This result is corroborated by the softer polymeric structure of the $\mathrm{CF}_{\mathrm{x}}$ films with $\mathrm{F}$ concentrations above $\sim 25$ at. \% synthesized by others [14, 16, 17], and in our group [18].

Contrary to patterns B and C, the large N-member ring defect, assigned here as pattern A, only adds to the local curvature of the graphene-like sheet but does not bring any 
structural disorder or disruption to the graphene-like sheets. Thus, some of the structural patterns associated with $\mathrm{F}$ incorporation in $\mathrm{CF}_{\mathrm{x}}(\mathrm{B}, \mathrm{C})$ promote amorphization of the compound with emphasis to elements of polymeric structure (B), while others (A) contribute to conserving the integrity of the graphene-like network.

By considering the calculated gains in cohesive energy corresponding to patterns $\mathrm{A}, \mathrm{B}, \mathrm{C}$, and D (see Table 1), the structural implications of these patterns, and also taking into account the F concentrations adopted for the studied model systems, conclusions can be drawn for the relation between the $\mathrm{F}$ concentration in a given $\mathrm{CF}_{\mathrm{x}}$ system and its predominating structure. For $\mathrm{F}$ concentrations $\sim 10$ at. $\%$, which corresponds to approximately $1 \mathrm{~F}$ atom per each $10 \mathrm{C}$ atoms, while some $\mathrm{F}$ atoms would induce defects pointing to amorphyzation of the $\mathrm{CF}_{\mathrm{x}}$ film, many of the incorporated $\mathrm{F}$ atoms will only increase the graphene-like sheet curvature thus inducing FL types of defects in the sense of Refs. $[4,6,7]$ without radically disrupting the graphene-like $\mathrm{CF}_{\mathrm{x}}$ network. At lower $\mathrm{F}$ concentrations of $\sim 3-8$ at. $\%$, the $\mathrm{CF}_{\mathrm{x}}$ films are expected to be even more ordered and to exhibit a moderately cross- and interlocked FL structure similar to that of the wellstructured FL-CP ${ }_{\mathrm{x}}[6]$. Such considerations for the degree of the "Fullerene-likeliness" of the $\mathrm{CF}_{\mathrm{x}}$ system will be only valid if two or more defects belonging to the patterns A-D could coexist in close vicinity to each other, conserving their structural integrity and without merging together. Contrarily, if such adjacent defects evolve toward merging, this would bring an additional amorphousness to the network, favoring almost certainly an amorphous structure even at concentrations of $\mathrm{F}$ atoms as low as $\sim 5$ at. $\%$.

In order to test how stable the closely located defects are, we considered two model 
systems containing two, and three typical $\mathrm{CF}_{\mathrm{x}}$ structural patterns, respectively. In Fig. 3a and Fig. 3b, the left panels exhibit the model systems before relaxation, while the right panels show the corresponding optimized configurations. A comparison between the left and the right panels in Fig. 3 illustrates that closely located defect patterns in a $\mathrm{CF}_{\mathrm{x}}$ system tend to conserve their integrity and do not merge nor evolve toward amorphization. A typical value for the gain in $\mathrm{E}_{\text {coh }}$ associated with a relaxed system containing two or more stable together (i.e., not merging) $\mathrm{CF}_{\mathrm{x}}$ defect patterns is, e.g., $\Delta \mathrm{E}_{\text {coh/at }}=0.160 \mathrm{eV} / \mathrm{at}$ (Fig. 3b). Such energy values are of similar order of magnitude to the gain in cohesive energy (Table 1) associated with the formation of some of the individual $\mathrm{CF}_{\mathrm{x}}$ structural patterns (e.g., the one displayed in Fig. 2-b2) confirming that multiple defects can co-exist in close vicinity without evolving to amorphous structure.

As reported in our previous work, the precursors with major impact during magnetron sputtered deposition of $\mathrm{CF}_{\mathrm{x}}$ films (in $\mathrm{CF}_{4} / \mathrm{Ar}$ atmosphere) are the $\mathrm{CF}$, and the $\mathrm{CF}_{2}$ radicals, the $\mathrm{C}_{2}$ dimers, and to a lesser extent, the free $\mathrm{C}$ and $\mathrm{F}$ atoms, and the $\mathrm{CF}_{3}$ radicals [18]. The $\mathrm{CF}$ and $\mathrm{CF}_{2}$ radicals playing a decisive role as precursors for magnetron sputtered $\mathrm{CF}_{\mathrm{x}}$ thin films are not only highly reactive due to their dangling bonds, but they contain the all important for the $\mathrm{CF}_{\mathrm{x}}$ structural patterns, $\mathrm{C}-\mathrm{F}$ dimer/bond. This implies that the $\mathrm{C}$ F bond is mostly incorporated in the film as a pre-existing dimer and not created during the precursor's bonding at the film edge. Such a mechanism of F incorporation facilitates the C-F bond rotation and further corroborates our point about the importance of the C-F bond rotation for the prevailing $\mathrm{CF}_{\mathrm{x}}$ defect patterns. 


\section{CONCLUSIONS}

We addressed $\mathrm{CF}_{\mathrm{x}}$ thin films by applying SGC-based computer simulations. The prevailing structural patterns in $\mathrm{CF}_{\mathrm{x}}$ that result from incorporation of $\mathrm{F}$ atoms in a graphene-like network include: large $\mathrm{N}$-member $(\mathrm{N}=8-12)$ rings, a defect by branching of the model system which can result in formation of carbon chains or nano-ribbons/split and bent graphene sheets, as well as a C-F bond rotation strongly suggestive for intersheet cross-linkages. The cohesive energy gains associated with these defect patterns vary predominantly in the range of $\sim 0.2-0.4 \mathrm{eV} / \mathrm{at}$, which is comparable with the energy costs of a wide range of defects in C-based nanostructured compounds. A common feature of the defect patterns in $\mathrm{CF}_{\mathrm{x}}$ is the $\mathrm{C}-\mathrm{F}$ bond rotation. Instead of being formed at the growing film surface, a C-F bond is mostly "imported" to the magnetron sputtered (in $\mathrm{CF}_{4} / \mathrm{Ar}$ atmosphere) $\mathrm{CF}_{\mathrm{x}}$ films as an existing bond already present in the precursors available in the growth environment such as $\mathrm{CF}$ and $\mathrm{CF}_{2}$. Pentagon defects, so typical in FL-CN ${ }_{\mathrm{x}}, \mathrm{CP}_{\mathrm{x}}$, and $\mathrm{CS}_{\mathrm{x}}$ can be observed in $\mathrm{CF}_{\mathrm{x}}$, but in the peculiar shape of a pure carbon pentagon ring stabilized at the border of a large $\mathrm{N}$-member ring and opposite to a $\mathrm{C}-\mathrm{F}$ bond rotation. Different $\mathrm{CF}_{\mathrm{x}}$ defect patterns can coexist in close vicinity without merging thus preserving the system from full amorphyzation. Both this result and the particular stability of the large N-member rings favor an ordered FL structure. In contrast, the "branching" pattern promotes amorphous structure with elements of polymeric structure which are expected to become more pronounced as the $\mathrm{F}$ concentration increases. The simulation results suggest that $\mathrm{FL}-\mathrm{CF}_{\mathrm{x}}$ can be synthesized at $\mathrm{F}$ concentrations below $\sim 10$ 
at. \%. As expected, depending on the particular $\mathrm{CF}_{\mathrm{x}}$ model system and its selection of defects, the transition from FL to amorphous system with elements of polymeric structure does not happen always at the same $\mathrm{F}$ concentration, but corresponds to a range of $\mathrm{F}$ concentrations, normally, between 8 at. $\%$ and $12.5 \%$. Fluorine is an extremely reactive species and it is the most electronegative chemical element too, so it is not surprising that the $\mathrm{FL}-\mathrm{CF}_{\mathrm{x}}$ demands the lowest concentration of the dopant when compared to other FL compounds such as $\mathrm{CN}_{\mathrm{x}}$ (up to 30 at.\% of $\mathrm{N}$ ), $\mathrm{CP}_{\mathrm{x}}$ (up to 15 at.\% of $\mathrm{P}$ ), and $\mathrm{CS}_{\mathrm{x}}$ (up to 15 -18 at. $\%$ of S).

The described mechanisms of $\mathrm{F}$ incorporation in $\mathrm{CF}_{\mathrm{x}}$ and the richness of structural patterns in $\mathrm{CF}_{\mathrm{x}}$ thin films reveal a new compound with tunable structure (FL, polymeric, or amorphous) achieved by varying its $\mathrm{F}$ incorporation rate. The polymeric $\mathrm{CF}_{\mathrm{x}}$ may lead to a new material as significant as Teflon. Foreseen applications for $\mathrm{CF}_{\mathrm{x}}$ films include tuning their mechanical properties and surface energy by controlling the deposition conditions for, e.g., coating low-friction mechanical details, such as rolling and sliding bearings.

\section{ACKNOWLEDGEMENTS}

G.K.G. is grateful to the Swedish Research Council (VR). The authors gratefully acknowledge Functional Nanoscale Materials (FunMat) consortium - a VINN Excellence Center financed by the Swedish Governmental Agency for Innovation Systems (VINNOVA) and the European Research Council (ERC). The National Supercomputer 
Center in Linköping is acknowledged for providing high performance computing resources.

\section{REFERENCES}

[1] L. Hultman, J. Neidhardt, N. Hellgren, H. Sjöström, J-E. Sundgren, MRS Bull. 28 (2003) 194-202

[2] A. Furlan, "Fullerene-like $C N_{x}$ and $C P_{x}$ Thin Films; Synthesis, Modeling, and Applications". [Thesis]. Linköping: Linköping University Electronic Press; 2009. Linköping Studies in Science and Technology. Dissertations, 1247

[3] H. Sjöström, S. Stafström, M. Boman, J-E. Sundgren, Phys. Rev. Lett. Vol. 75, Num. 7 (1995) 1336-1339

[4] G.K. Gueorguiev, J. Neidhardt, S. Stafström, L. Hultman, Chem. Phys. Lett. 410 (2005) 228

[5] A. Furlan, G.K. Gueorguiev, H. Högberg, S. Stafström, L. Hultman, Thin Solid Films, 515 (2006) 1028-1032

[6] G.K. Gueorguiev, A. Furlan, H. Högberg, S. Stafström, L. Hultman, Chem. Phys. Lett. 426 (2006) 374-379

[7] C. Goyenola, G.K. Gueorguiev, S. Stäfstrom, L. Hultman, Chem. Phys. Lett. 506 
(2011) 86-91

[8] G.K. Gueorguiev, J. Neidhardt, S. Stafström, L. Hultman, Chem. Phys. Lett. 401 (2005) 288

[9] G.K. Gueorguiev, E. Broitman, A. Furlan, S. Stafström, L. Hultman, Chem. Phys. Lett. 482 (2009) 110

[10] G.K. Gueorguiev, J. M. Pacheco, S. Stafström, L. Hultman, Thin Solid Films, 515 (2006) 1192

[11] G.K. Gueorguiev, S. Stafström, L. Hultman, Chem. Phys. Lett. 458 (2008) 170

[12] Deepthi Jose and Ayan Datta, Phys. Chem. Chem. Phys. 13 (2011) 7304

[13] Vaisakh Mohan and Ayan Datta, J. Phys. Chem. Lett. 1 (2010) 136

[14] A. Bendavid, P.J. Martin, L. Randeniya, M.S. Amin, R. R., Diamond \& Related Materials/19 (2010) 1466

[15] L. Valentini, V. Salerni, I. Armentano, J.M. Kenny, L. Lozzi, S. Santucci, Journal of Vacuum Science \& Technology A 21/5 (2003) 1784

[16] M. Ishihara, M. Suzuki, T. Watanabe, T. Nakamura, A. Tanaka, Y. Koga, Diamond \& Related Materials /14 (2005) 989

[17] C.H. Lai, W.S. Lai, H.C. Chiue, H.J. Chen, S.Y. Chang, S.J. Lin, Thin Solid Films 
$510 / 1-2(2006) 125$

[18] S. Schmidt, G. Greczynski, C. Goyenola, G. K. Gueorguiev, Zs. Czigány, J. Jensen, I. G. Ivanov, L. Hultman, Surface \& Coatings Technology, submitted (2011)

[19] Haiyan Wei, David A. Hrovat, William R. Dolbier, Jr., Bruce E. Smart, and

Weston Thatcher Borden, Angew. Chem. Int. Ed. 46 (2007) 2666

[20] Haiyan Wei, David A. Hrovat, and Weston Thatcher Borden, J. Am. Chem. Soc. 128 (2006) 16676

[21] G. Robert Shelton, David A. Hrovat, Haiyan Wei, and Weston Thatcher Borden, J. Am. Chem. Soc. 128 (2006) 12020

[22] M.J. Frisch et al., Gaussian 09, Revision A.1, Gaussian, Inc.,Wallingford, CT, 2009

[23] Ljubisa R. Radovic, J. Am. Chem. Soc. 131 (2009) 17166

[24] George M. Psofogiannakis and George E. Froudakis, J. Am. Chem. Soc. 131 (2009) 15133

[25] R. Rivelino, Renato B. dos Santos, F. de Brito Mota, G. K. Gueorguiev, J. Phys. Chem. C 114 (2010) 16367

[26] J. P. Perdew, J. A. Chevary, S. H. Vosko, K. A. Jackson, M. R. Pederson, D. J. Singh, and C. Fiolhais, Phys. Rev. B 46 (1992) 6671 
[27] A. D. Becke, J. Chem. Phys. 98 (1993) 5648

[28] S. Stafström, L. Hultman, N. Hellgren, Chem. Phys. Lett. 340 (2001) 227

[29] R.-H. Xie, G.W. Bryant, L. Jensen, J. Zhao, V.H. Smith Jr., J. Chem. Phys. 118 (2003) 8621

[30] R.-H. Xie, G.W. Bryant, V.H. Smith Jr., Chem. Phys. Lett. 368 (2003) 486

[31] A.L.E. Garcia, S. E. Baltazar, A.H. Romero, J.F. Perez Robles, and A. Rubio, Journal of Computational and Theoretical Nanoscience 5 (2008) 1

[32] S.R.J. Pearce, P.W. May, R.K. Wild, K.R. Hallam, P.J. Heard, Diam. Relat. Mater. $11(2002) 1041$

[33] An introduction to polymer physics, David I. Bower, Cambridge University press, 2002 


\section{TABLE CAPTIONS}

Table 1. PW91 cohesive energy gains $\Delta \mathrm{E}_{\mathrm{coh} / \mathrm{t}}$ associated with the formation of the typical $\mathrm{CF}_{\mathrm{x}}$ structural patterns. See main text for details. 


\section{TABLES}

Table 1.

\begin{tabular}{llc}
\hline \multicolumn{1}{c}{ Description of the pattern } & Pattern & \multicolumn{2}{c}{ Cohesive Energy Gain } \\
& A & $\Delta \mathrm{E}_{\text {coh/at }}$ (eV/at) \\
\hline 9-member ring with C-F bond rotation (Fig. 2-a1) & A & 0.405 \\
\hline $\begin{array}{l}\text { 9-member ring with formation of pure carbon } \\
\text { pentagon (Fig. 2-a2) }\end{array}$ & A & 0.190 \\
\hline Branching - carbon chains (Fig. 2-b1) & B & 0.383 \\
\hline $\begin{array}{l}\text { Branching - ribbon chains (sequence of hexagons) } \\
\text { (Fig. 2-b2) }\end{array}$ & B & 0.161 \\
\hline $\begin{array}{l}\text { "Simple" C-F bond rotation - C belongs to a ring } \\
\text { (Fig. 2-c1) }\end{array}$ & C & 1.001 \\
\hline $\begin{array}{l}\text { "Simple" C-F bond rotation - C attached externally } \\
\text { to a ring (Fig. 2-c2) }\end{array}$ & C & 0.296 \\
\hline \begin{tabular}{l} 
F included in a ring (Fig. 2-d) \\
\hline
\end{tabular} & D & 0.079 \\
\hline
\end{tabular}




\section{FIGURE CAPTIONS}

Figure 1. Model systems representing: a) coronene; b) corannulene; c) double pentagon defect; d) Stone - Wales defect; e) pure hexagon network; f) single pentagon defect. White atoms represent $\mathrm{H}$, while grey ones correspond to $\mathrm{C}$.

Figure 2. Examples of $\mathrm{CF}_{\mathrm{x}}$ structural patterns arising from the incorporation of $\mathrm{F}$ atoms in a graphene-like network: a1) a large 9-member ring (the inset represents an inclined view of the same pattern illustrating its curvature), and a2) a large 9-member ring adjacent to a pure carbon pentagon. Both structures belong to pattern A; b1) branching in two symmetrical chains, and b2) branching in two symmetrical ribbons of hexagons. Both structures belong to pattern B; c1) and c2) two variants of an "uncomplicated" C-F bond rotation - pattern $\mathrm{C}$; d) $\mathrm{F}$ atom included in a ring - pattern $\mathrm{D}$. White atoms represent $\mathrm{H}$, while grey and black ones correspond to $\mathrm{C}$, and F, respectively. See main text for details.

Figure 3. Model systems unifying: a) two, and b) three defects induced by incorporation of $\mathrm{F}$ atoms in graphene-like network. The left panels show the model systems before the optimizations and the right panels display the corresponding relaxed systems. The insets represent inclined views of the corresponding model systems illustrating their curvature. White atoms represent $\mathrm{H}$, while grey and black ones correspond to $\mathrm{C}$, and $\mathrm{F}$, respectively. 


\section{FIGURES}

a) $\begin{array}{ll} & 6\end{array}$

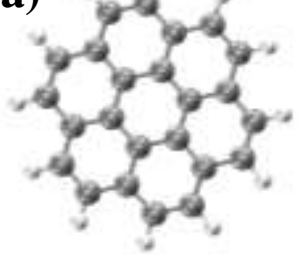

d)

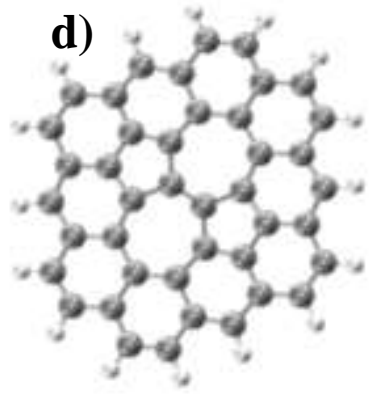

e)

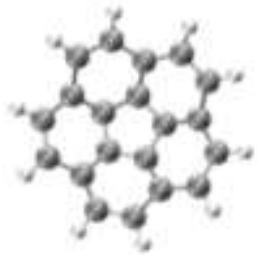

c)
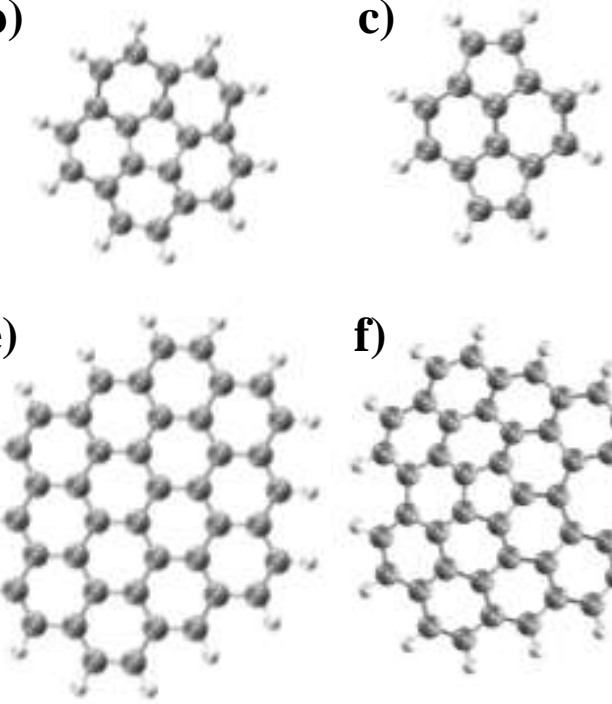

f)

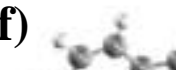

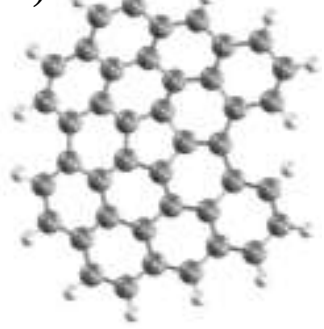

Figure 1 


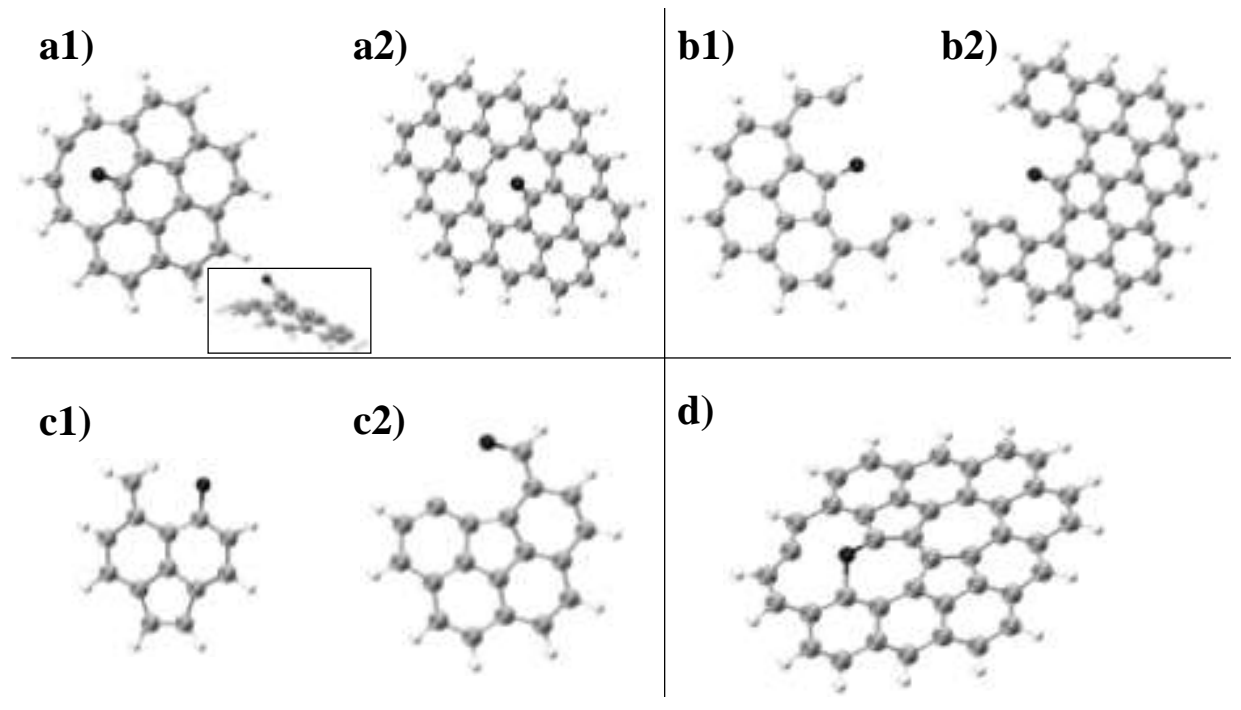

Figure 2 
a)

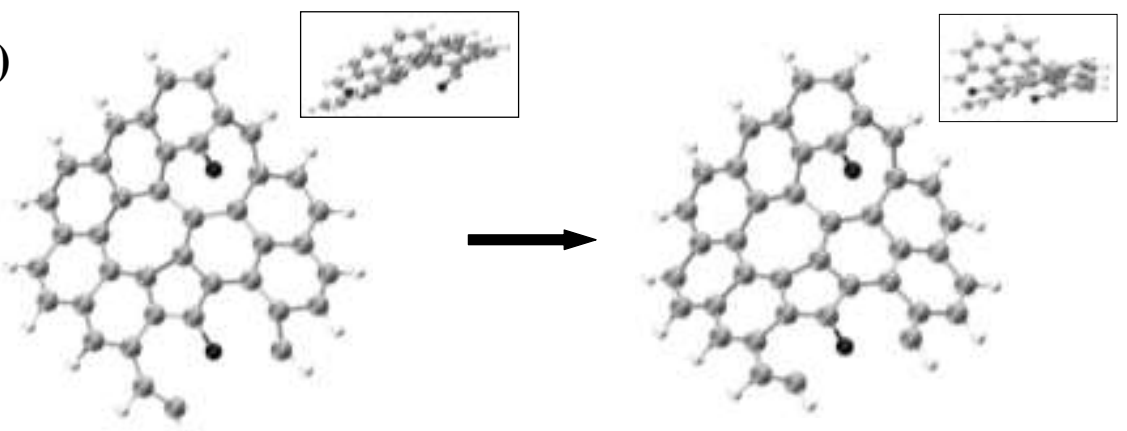

b)

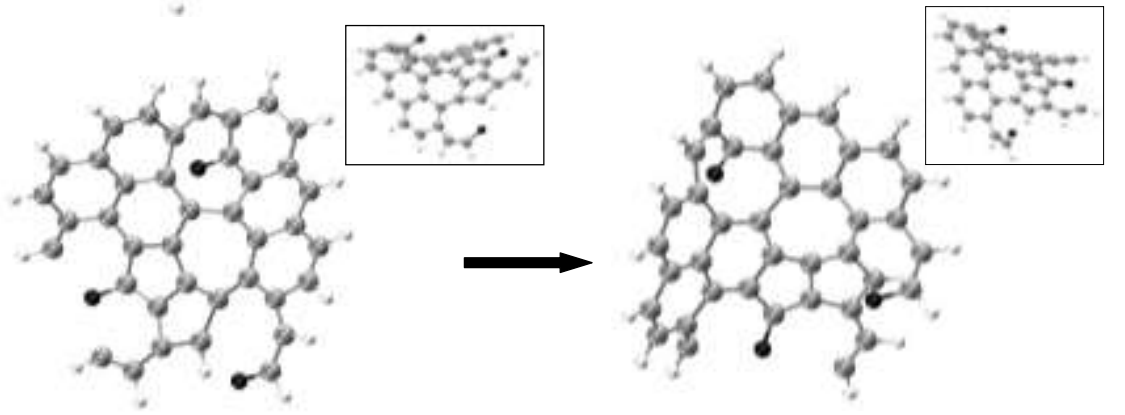

Figure 3 